\title{
Redesign of a Traditional Ritual Furnace for Reducing Environmental Impact
}

\author{
Wei-Long Chen, Cheng-Chi Chang, and Fang-Lin Chao
}

\begin{abstract}
The practice of burning gold paper in Taiwan is a profound yet common culture event, but it causes air pollution and, thus, environmental impact. The design scheme preserves the traditional customs and reduces the smoke and tiny particles diffused to the ambient air. Concept design-I is a rectangular tube structure with a partition frame to form a second combustion chamber. These partitions need a place among the internal space. Concept design-II uses a circular tube structure with better aesthetic expression. But the fabrication accuracy and installation of a circular structure are troublesome to achieve. We choose the concept-I as the implemented model. The functional model has shown much less smoke generated with the help of a secondary combustion chamber.
\end{abstract}

Index Terms-Ritual furnace, environmental impact, redesign, combustion chamber.

\section{INTRODUCTION}

Ancestral worship is a traditional ritual in Chinese culture. "Burn the Gold paper" is a tribute and blessing to the deceased. In traditional Chinese religion, people believe that the living, the dead, and the gods coexist in the vast world. Burning paper and offerings of paper houses and paper cars are considered to help the spirit in the other world [1], [2]. The offerings item included paper money, paper coins, paper gold, and even paper credit cards. Chinese Americans and immigrants also practice these rituals in bereavement. [3].

In Taiwan, where the living environment is narrow, and houses are usually right next to each other, the practice of burning gold paper may often draw protests from neighbors. The practice of burning gold paper in Taiwan is deeply rooted in traditional culture. However, the by-product of this practice is a disturbance to the local air quality. [4]. The design scheme attempts to preserve traditional customs while reducing the environmental impact.

\section{PRoBlem IDENTIFICATION}

\section{A. Previous Cases}

Fig. 1 shows the Green gold stove applied the smoldering way, with the lower air intake proceed as the flames continue to burn in the furnace. The gold papers are placed on the ring frame, which has a porous air duct in the middle (Fig. 2). There is a stand-up bracket below the cylindrical furnace body. The gold paper is placed on the elevated bracket and

Manuscript received September 9, 2019; revised December 11, 2019.

The authors are with the Department of Industrial Design, Chaoyang University of Technology, Taichung, Taiwan (e-mail: flin@ cyut.edu.tw). does not block the air intake. Thus, the cold air can flow upward from the central air duct so that the airflow path of the air intake is relatively smooth.

As shown in Fig. 3, this is the golden stove we observed in the open space outside the community. The community people came to burn gold paper, and we found that a lot of ash fell below, even under the furnace. Since the removal of ash often causes cough and discomfort, no one takes the initiative to remove it. The soot has blocked the lower vent and lost the original ventilation convection function. People excavates ash through this door. Incomplete burn causes the side air to flow and generate more particles.

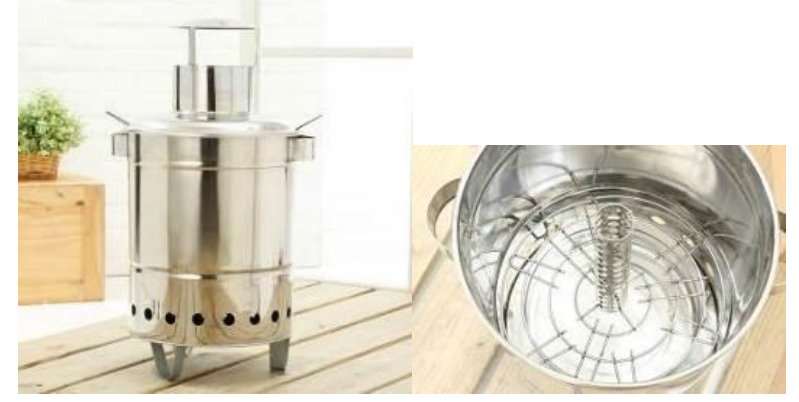

(a)

(b)

Fig. 1. The structure of a green furnace.

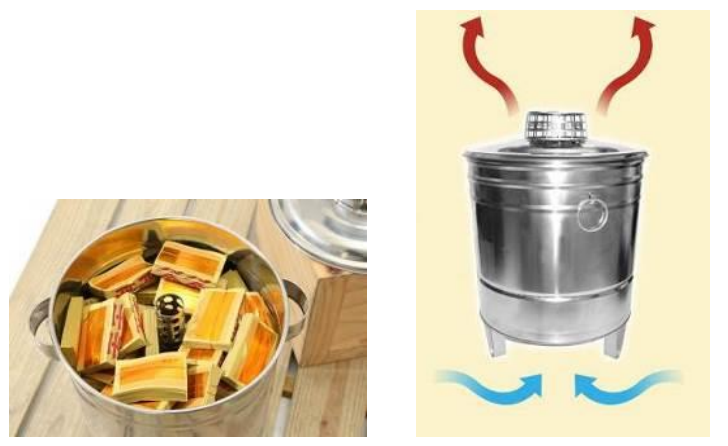

Fig. 2. Cold air goes upward from the middle duct.

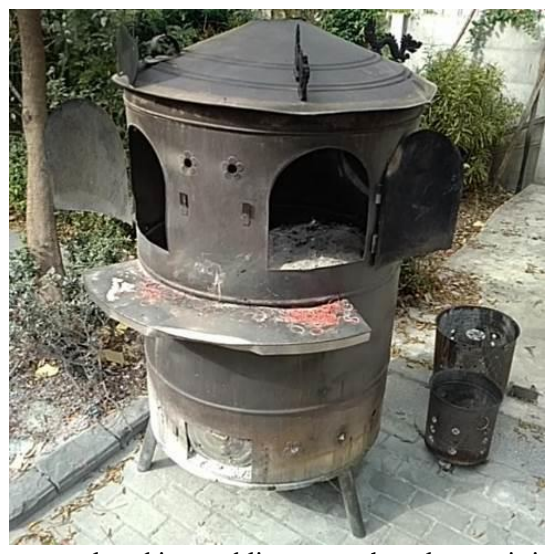

Fig. 3. A furnace placed in a public space where lower air intakes were blocked. 


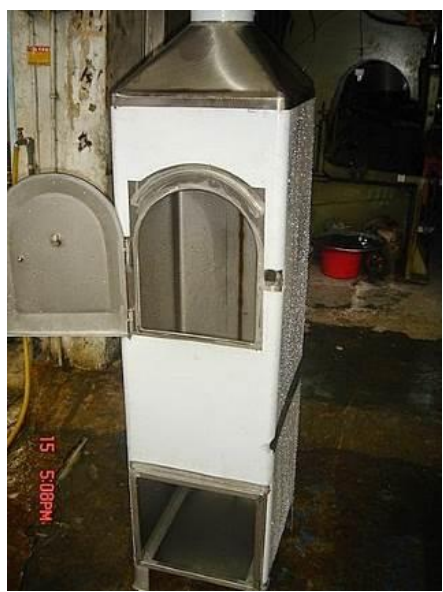

Fig. 4. Square furnace: Custom-made for people living in homes with narrow spaces.

Fig. 4 shows a custom-made furnace for reducing particles. Water adsorption can filter out waste smoke. However, due to the need for additional piping coordination, the installation price is very high.

The intake of gold paper is relatively high. The users bend their body to put in the paper. The lower air intake is high and will not block by the ensuing debris, ensuring adequate airflow. There is a towering chimney on top that provides the chimney effect, making convection smoother but increasing its cost.

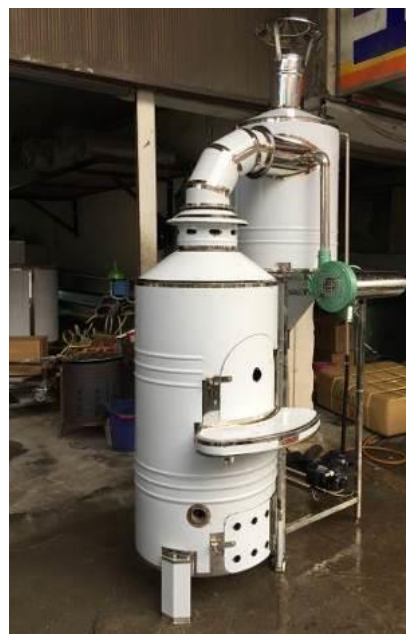

Fig. 5. Gold stove with spraying water to reduce particles.

Referring to Fig. 5, the design includes two central bodies, a combustion furnace, and a precipitation furnace. In the middle of the burner on the left side is the paper input port, and below it is the outlet for burning the ash. The burning ash is led out from the upper cylindrical channel to the right sedimentation tank. There is a mechanism for spraying water in the barrel so that the burnt ash will be absorbed by the water mister deposited downward. Therefore, the composition and proportion of the ash in the upper exhaust gas significantly reduced.

The above example shows:

- Many smokeless gold stoves are similar to smoldering burning by control the gold paper in a confined space to extend the burning time.

- The smokeless gold stove must cooperate with installation conditions. Because the furnace body connected to the existing exhaust pipe, it cannot be moved at will.

- The configuration of the pipeline adds a lot of costs and also causes a substantial increase in volume, which is the main problem of the existing smokeless gold furnace. The entrance of gold paper and the outlet of flue gas in many small gold furnaces are set in the same region and reducing the chimney effect.

Both separating inlet/exit and increasing the channel's height help to achieve the chimney effect results in a faster burning rate.

\section{B. The by-Product of the Burning}

Burning incense and burning gold paper have an impact on the environment, so Taiwan's air quality standards have set requirements standards. During the Lunar New Year, Ching-Ming Festival and the Moon Festival is the period of the highest consumption of gold paper. The average household use in Taiwan is $0.3,1.2$, and $2.0 \mathrm{~kg}$, respectively

[5]. The byproduct of its combustion is [6]:

1) The average concentration of flue gas is: NOx is 37.5 ppm, $\mathrm{SO}_{2}$ is $429 \mathrm{ppb}$, The $\mathrm{CO}$ concentration is $1,060 \mathrm{ppm}$, which has a significant influence on air quality.

2) The average level of flue gas incense is: NOx $2.3 \mathrm{ppm}$, $\mathrm{SO}_{2}$ to $88.2 \mathrm{ppb}$, The $\mathrm{CO}$ concentration is $422 \mathrm{ppm}$. Burning in a combustion chamber showed that the level of GEM from burning ranged from 4.07 to $11.62 \mu \mathrm{g} / \mathrm{m} 3$. Mercury emitted had a significant influence on the air concentrations in a temple [6].

3) Burning gold paper with GC/MS contains n-hexane, toluene, benzene, and other volatile organic compounds. The particle size distribution of suspended particulates is approximately $0.56 \mu \mathrm{m}$ to $3.2 \mu \mathrm{m}$ [7]. The cytotoxicity of indoor air pollutants was from biomass combustion [8].

\section{OBSERVATION AND DESIGN}

Waste smoke and ashes are the product of the incomplete combustion of the gold paper. Usually, incomplete combustion is difficult to avoid. The original material of gold paper mostly made of recycled paper. If we use high-quality paper fiber, the material cost will inevitably increase. The existing methods of purifying waste smoke include two times burning, washing smoke screen, anion smoke, electrostatic smoke, etc. However, these additional parts significantly increase the cost.

The design goal is to improve the combustion mode in the gold furnace, increase the degree of paper burning, and reduce the harm to the surrounding environment. The approaches included:

1) the concept is proposed, with the possibility of smoke removal.

2) Change the inner structure of the furnace, increasing the degree of the gold paper burning.

3) The actual production of the experimental prototype, detection of waste smoke drift way, needs individual control of the path of the waste smoke.

This design tries to reduce the by-products of the gold furnace. Under the premise of retaining the ceremony, reduce the physiological burden of combustion products with acceptable costs. Through the chimney effect and internal 
structural adjustment, the waste smoke flow path guided to the flame emitter, and the secondary combustion triggered at a high temperature. The existing products have a multi-round shape and a more upper gold furnace. Conceived development: guide the waste smoke to the flame launching port with the guide plate, and carry out secondary combustion to reduce the by-product emissions of combustion.

\section{A. Concept-I}

Fig. 6 shows the design of concept-I. It is a square structure with a long strip for air convection. It follows the idea of a traditional home temple, decorated with roof tiles and windows. The advantage of concept-I is that the stainless steel metal parts are relatively easy to manufacture and assembly. It is also not easy to be damaged during a collision.

As shown in Fig. 7, the internal structure provides a secondary combustion area. In this design, we offer a buffer zone for the second combustion. How did it do it? First, we added several partitions in the combustion chamber to allow the hot gas to flow upward slowly. The temperature of the combustion by-products gradually increases during the flow. These high-temperature by-products are ignited again at the top turn. The ash burned for the second time with the igniter, so the discharged ash reduced. At the bottom right of Fig. 6 is a gas canister that provides fuel to ignite the gas. We will open this combustion-supporting device to achieve the goal of increasing the combustion ratio.

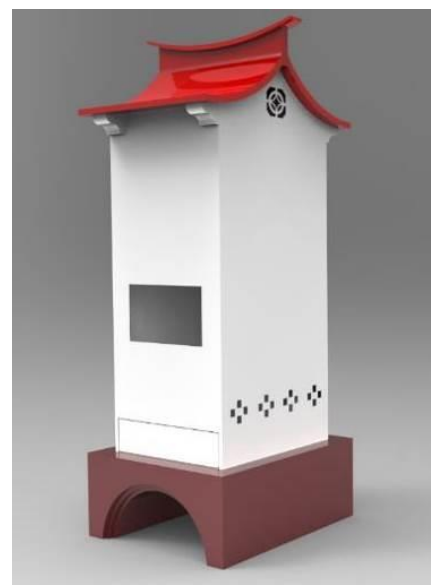

Fig. 6. Concept design- I.

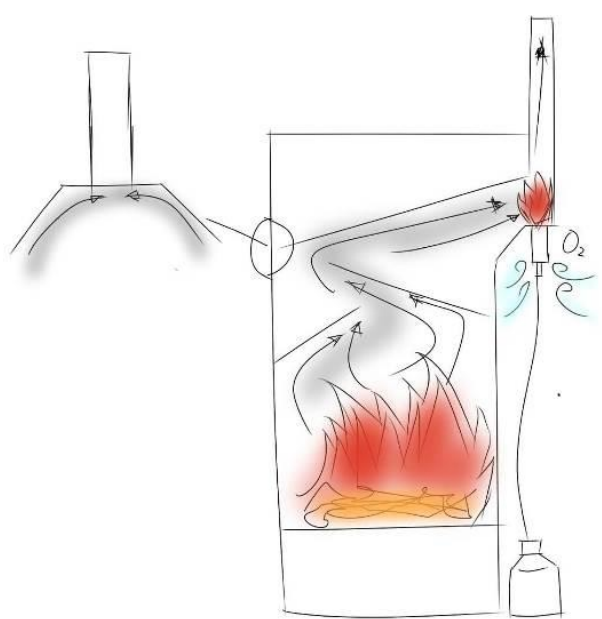

Fig. 7. The concept I: Internal structure, secondary combustion schematic.

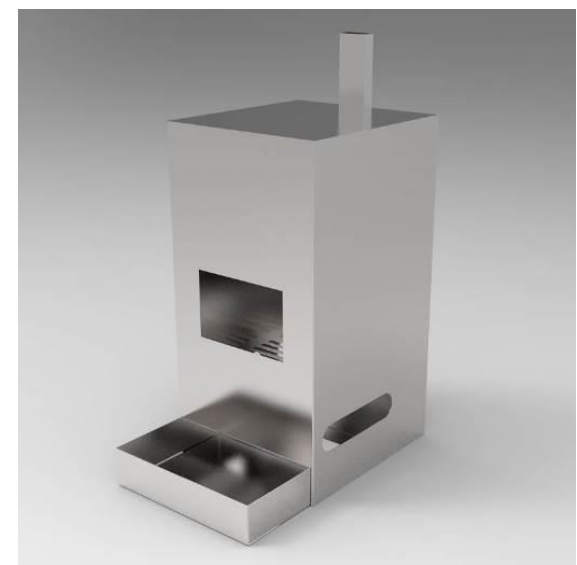

Fig. 8. The Concept-I: Overall composition and secondary combustion chamber sectional view.

The design concept is appropriate for guiding the airflow and increasing the combustion rate. Fig. 8 shows a 3D model of the overall composition and secondary combustion chamber. First, in the path of rising airflow, we add staggered dividers. The flow rate of natural convection will slow down along the serpentine flow path. A secondary combustion chamber placed in the transition area. The gas flow rate slows down, and the temperature is also high enough. At this time, the Jet rifle ignited again; the residual particles burn and flow along with the discharge chimney.

\section{B. Concept Design-II}

Concept II is a circular structure, the overall appearance of the surrounding feeling (Fig. 9). The surface of the gold part of the stainless steel plate below is a Buddhist verse formed by laser cutting, which is compatible with the themes of religion. The middle section is the place where the gold paper sent, the cold air entered from the bottom, the top is flowing upward, and the upper part is the tubular smoke vent. In this way, the elders do not have to bend over and fit the physical condition. When burning, the user closes the door, and some of the burnt ashes stored in a lower drawer that can be pulled out.

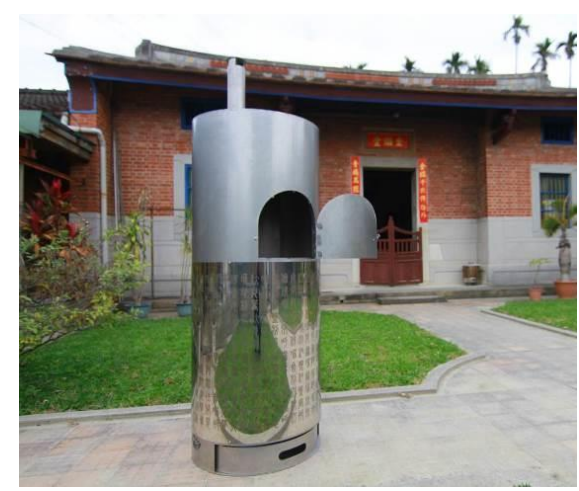

Fig. 9. Concept-II: using situational emulation.

\section{PRototyping And Testing}

We built a square model of concept-I. The internal structure of the prototyping model made of sheet metal. Since it is a fire-related product, the users need to pay attention to safety. The improved design needs to control the cost, which cannot be much higher than that of the existing stove. 
Consumers will accept environmentally friendly furnace. We adjusted the parameters of the product through experiments.

To facilitate the observation of the smoke flow; we use a transparent acrylic material on a side wall at the initial test. The smoke slowly flowed up along the guide piece, and after the ignition in the secondary combustion area, the amount of smoke coming out reduced. Fluid continuity indicates that the total amount of intake air is equal to the total amount of outgassing. We observed the by-products of combustion at the outlets (Fig. 10a). We estimate the particle content of the smoke using the optical probe with a fixed light source and a receiving light sensor. The received light intensity is inversely proportional to the concentration within the smoke. We found that the number of particles in the new design reduced (Fig. 10b).



(b)

Fig. 10. The institutional model of the square proposal: (a) smoke of tradition structure, (b) much less smoke with a secondary combustion chamber.

The pre-estimated cost is still high, so we reduce the complexity of form and processing to simplify parts and minimize cost. Which structure is most suitable for the construction of the furnace? It should not judge by the absolute value of the amount of smoke exhausted.

Considering a relatively low smoke generate at an appropriate cost. According to the amount of gold paper used by Taiwanese family festivals and the height required for the chimney effect, plus the space needed for the sale of gas tanks, we set the size of the gold furnace to $55 \mathrm{~cm} \times 56 \mathrm{~cm} \times 160 \mathrm{~cm}$ (width $\times$ depth $\times$ height). The cost of the stove reduced to the market's acceptable range.

\section{CONCLUSIONS}

The golden stove placed in open space outside the community. Sometimes the soot blocked the lower vent. When the paper burned incompletely, more particles generated. The design goal is reducing by-products. Through the chimney effect and internal structural adjustment, the waste smoke flow path guided to the flame emitter, and the secondary combustion triggered at a high temperature.

Concept-I is more feasible to implement. Because in the interior of the gold furnace, we added a partition and a second combustion chamber in the space area associated with it. These partitions placed in several positions in the internal space. Concept II uses a circular design, and the fabrication accuracy and installation of these partitions are prone to trouble. These production and installation problems are enough to increase the cost of production; therefore, from a functional point of view, the concept one is a more suitable design proposal.

\section{CONFLICT OF INTEREST}

The authors declare no conflict of interest.

\section{AUTHOR CONTRIBUTIONS}

Chen and Chao conducted the research; Chang designed the system; all authors had approved the final version.

\section{REFERENCES}

[1] C. Cecilia et al., "The experience of Chinese bereaved persons: A preliminary study of meaning-making and continuing bonds," Death Studies, vol. 29, no. 10, pp. 923-947, 2005.

[2] C. K. Yang, "Religion in Chinese society: A study of contemporary social functions of religion and some of their historical factors," Master thesis, University of California Press, 1967.

[3] A. G. Yick and R. Gupta, "Chinese cultural dimensions of death, dying, and bereavement: Focus group findings," Journal of Cultural Diversity, vol. 9, no. 2, p. 32, 2002.

[4] Y. H. Jiang et al., "Study on the influence of emissions from gold furnace burning gold paper on air quality," M.S. thesis, Department of Environmental Engineering and Management, Chaoyang University of Science and Technology, Taichung, 2006.

[5] X. Zhou et al., "The reduction of air pollutants produced by burning gold paper, worship and firecrackers and hazard assessment sub-project 1: Component analysis and emissions estimation of air pollutants," M.S. thesis, Department of Environmental Engineering, National Cheng Kung University, 2007.

[6] C. He et al., "Characterisation of the impact of open biomass burning on urban air quality in Brisbane, Australia," Environment International 91, pp. 230-242, 2016.

[7] Y. H. Jen et al., "How incense and joss paper burning during the worship activities influences ambient mercury concentrations in indoor and outdoor environments of an Asian temple?" Chemosphere, vol. 167, pp. 530-540, 2017.

[8] R. Ganesh et al., "Effect of equivalence ratio on gasification of granular biomaterials in self-circulating fluidised bed gasifier," International Journal of Environment and Sustainable Development, vol. 17 , no. 2,2018

Copyright (C) 2020 by the authors. This is an open access article distributed under the Creative Commons Attribution License which permits unrestricted use, distribution, and reproduction in any medium, provided the original work is properly cited (CC BY 4.0).

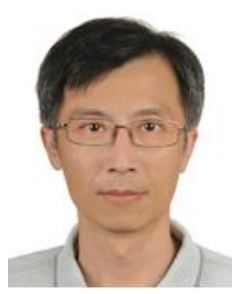

Wei-Long Chen received a Ph.D. degree in aerospace engineering from the University of Oklahoma. He was a researcher of MSC software; he also served as a consultant in the company such as Pro-Iroda, Grand Mate, and aerospace institute.

$\mathrm{He}$ joined National Center for High-Performance Computing, Hsinchu, Taiwan. Since September 1999, he has been an Associate Professor with the Department of Industrial Design at Chaoyang University of Technology, Taichung, Taiwan. His research interests include $\mathrm{CAE}$ and product development. 


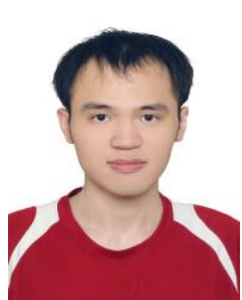

Cheng-Chi Chang graduated from the Department of Industrial Design at Chaoyang University of Technology, Taiwan, in 2017. He is a design assistant in the $\mathrm{R} \& \mathrm{D}$ department of woodworking machinery company. Currently, he is a master student supervised by Prof. Chen. His research interests include machine design, $\mathrm{CAD}$, and product development.

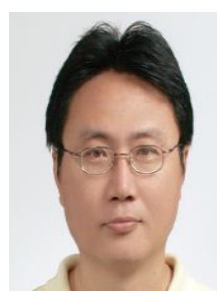

Fang-Lin Chao received the Ph.D. degree in electrical engineering from National Taiwan University. He joined the Electronic Research and Service Organization, Industrial Technology Research Institute, Hsinchu, Taiwan, in 1982. In 1994, he was an associate professor at Da-Yeh University. Since September 2004, he joined Chaoyang University of Technology. His research interests include eco-design and design integration. 